\title{
Paideusis
}

\section{Educating Moral Emotions}

\section{Debra Shogan}

Volume 2, Number 1, 1988

URI: https://id.erudit.org/iderudit/1073419ar

DOI: https://doi.org/10.7202/1073419ar

See table of contents

Publisher(s)

Canadian Philosophy of Education Society

ISSN

0838-4517 (print)

1916-0348 (digital)

Explore this journal

Cite this article

Shogan, D. (1988). Educating Moral Emotions. Paideusis, 2(1), 15-28.

https://doi.org/10.7202/1073419ar

(c) Debra Shogan, 1988

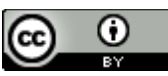

This document is protected by copyright law. Use of the services of Erudit (including reproduction) is subject to its terms and conditions, which can be viewed online.

https://apropos.erudit.org/en/users/policy-on-use/ 


\section{Educating Moral Emotions ${ }^{1}$}

\section{Debra Shogan, University of Alberta}

Before saying something about what an emotion is, what a moral emotion is, and why educating the moral emotions is important, I will comment briefly on moral motivation since, as 1 argue later, moral emotions are conceptually linked to moral motivation.

Moral situations tend to be of two general types. There are those situations in which others are, for example, injured, starved, homeless, distraught, lost, confused, tormented and the like, or in which they do not suffer but there is an opportunity for them to flourish. In this first type of moral situation, the welfare of sentient beings is at stake. When a moral person is confronted with this type of situation, a desire for the welfare of those in the particular situation amounts to a desire to help, or, if one is not in a position to help, a desire that someone else helps. This desire for the welfare of sentient beings is a benevolent desire and a moral response to this type of situation is a benevolent response. The second type of moral situation is one in which there is a conflict which requires adjudication. When a moral person is faced with this type of situation, a desire that those in the conflict are treated fairly amounts to a desire to be fair if one is an adjudicator, or a desire that others be fair when they adjudicate. A desire for fair treatment is a just desire and a moral response to the situation is a just response.

In order to respond morally to a situation, someone must not only understand that a particular situation is a moral one, he or she must desire that those in the moral situation, are treated well or fairly. To be motivated to respond morally to a particular moral situation entails that one has beliefs about the context in which a response would be appropriate (including beliefs about what makes a particular situation a moral one) and a desire to respond within this context. When a moral person is confronted with a situation which requires a benevolent response, the motivating reason to respond consists of understanding relevant beliefs associated with what makes the particular situation an instance in which welfare is at stake, and a desire that the welfare of those in the situation is enhanced. When a moral person is confronted with a moral situation which requires a just response, the motivating reason to respond consists of understanding relevant beliefs associated with what makes the particular situation an instance in which fair adjudication is an issue and a desire that those in the conflict are treated fairly.

Without a desire to help or adjudicate fairly, there is no moral response. Moreover, as $\mathbf{I}$ will show, without a desire to help or adjudicate, there is no experience of a moral emotion. In order to es- 
tablish this I must develop a conceptual understanding of what an emotion is. I will do this by discussing the following:

1) the relationship of emotion to feelings;

2) the relationship of emotion to behaviour;

3) the relationship of emotion to beliefs, evaluations and desires;

4) the relationship of emotion to motivation.

\section{The Relationship of Emotion to Feelings}

Emotions are not identical to feelings but feelings are experienced by someone who has an emotion. If, for example, I am anxious about someone driving through a storm, I experience certain sensations. Or, if I regret having treated someone poorly, I experience certain other sensations. There are those who argue, however. that feeling is not a necessary part of an emotion.

If $\mathrm{P}$ comes upon $\mathrm{Q}$ just as $\mathrm{Q}$ is setting fire to $\mathrm{P}$ 's house, and $P$ rushes at hin in blind fury, it seems singularly inappropriate to insist that $P$ must be having certain sensations. In fact $P$, in such circumstances, probably experiences no sensations of any kind, and yet he is undoubtedly extremely angry. 2

It is not improbable that someone may not be aware of what he or she is feeling because of being so intent on something else. $P$ may not be aware of his feelings because his attention is directed at punishing $Q$. But if someone does not experience any out of the ordinary feelings, even if momentarily oblivious of them, it is difficult. to see how we could understand that person as experiencing an emotion.

Experiencing an emotion as a feeling does not mean, of course, that an emotion can be reduced to the feeling involved in physiological or mental changes. I reject the view expressed by William James, for example, that "bodily changes follow directly the perception of the exciting fact, and ... our feeling of the same changes as they occur is the emotion.",3

There are a number of reasons, both empirical and conceptual, why emotions and feelings are not identical. Experimental evidence shows that "the same visceral changes occur in very different emotional states and in non-emotional states." 4 Furthermore, it is possible to drug induce feelings of anger or fear without the individual actually being angry or fearful. Moreover, if emotions were reducible to characteristic feelings, it would not be possible to make the conceptual distinctions we do make between emotions which have very 
similar feelings. The physiological or mental feelings associated with envy and jealousy, for example, do not differ much, if at all, and consequently it is not these feelings which distinguish envy from jealousy.

\section{The Relationship of Emotion to Behaviour}

The reduction of emotion to certain types of behaviour can also be dismissed on experiential and conceptual grounds. Emotions are not always expressed either facially or as overt actions. This is not to say that behaviour may not be helpful in interpreting another's emotions. There is, however, no one set of behaviours or changes in facial expression which are indicative of a particular emotion. Some emotions - for example, wonder and grief - may have no other behavioural manifestation than quiescence. 5 That a conceptual distinction can be made between wonder and grief even though their behavioural manifestations are the same illustrates that behaviour is not necessary to identifying a particular emotion.

There is, then, a difference between the experience of an emotion and its display. If someone is described as unemotional, this may only describe the person's display of emotion and not his or her experience of emotion. Someone may experience emotion and not display it either because of an ability to control its display or because of an inability to express emotion. Later $I$ will discuss the role of education in both the control and expression of moral emotions.

\section{The Relationship of Emotion to Belief, Evaluation, and Desires}

There is a formal relationship between the conceptual understanding of a particular emotion and its object. For example, the object of one's embarrassment is something which is awkward or unpleasant; the object of one's fear is something which is threatening. This formal relationship between an emotion and an object is, of course, not adequate for someone to experience an emotion. A person must also have relevant beliefs about the object and evaluate these beliefs in a certain way. For example, in order for Jane to be angry at her child for spilling his supper on the rug. Jane must believe that there is something spilled on the rug and she must believe that her child spilled it. She can be mistaken in her beliefs. She may believe the child spilled the supper when, in fact, the cat did. Different evaluations of the same beliefs result in different emotions. The "object" of fear, for example, is something which is threatening but only if one evaluates the situation as being threatening. I may believe that there is a mother bear on the path but as- 
sess at as agreeably dangerous and experience excitement rather than fear. 6

... emotions are not differentiated by means of the object or even the subject's factual beliefs about the object but by means of the subject's evaluative beliefs about the object .... For your emotion is, say, not one of embarrassment unless you evaluate or view the situation as awkward or unpleasant. If you were thick-skinned and did not mind in the least meeting people whom you had rejected or failed in some way, then you would not evaluate such meetings as awkward and unpleasant, and so would not be embarrassed in such situations. ${ }^{7}$

In order for Jane to be angry about the spilled supper, she must evaluate her beliefs about the spilled supper, she must evaluate her beliefs about her child spilling his supper as disagreeable. If she evaluates the same beliefs about the spilled supper as an indication of the child's independence, she may experience something like pride.

There are also different experiences of emotion depending upon what a person desires. Jane will experience pride in her evaluation of her child being independent, for example, only if she desires that the child be independent. If she does not desire this, she will experience something like annoyance.

Emotion is, then, a feeling one experiences when one has a particular desire, has beliefs about an object or event, and evaluates these beliefs in a certain way. I desire not to be harmed and I believe that this is an animal with very sharp teeth. If I also evaluate the animal as threatening, I experience fear. Fear just is the feeling one experiences when one desires not to be harmed when evaluating something as threatening. This is not to say that all combinations of desires and beliefs have a corresponding emotion. They do not. But all emotions entail a corresponding desire and evaluated beliefs. ${ }^{8}$

Emotion is often contrasted to reason in such a way that it is often thought that, if someone is emotional, he or she is not reasonable. I have shown, on the other hand, that emotions are a necessary result of certain types of motivating reasons. Emotions can sometimes be unreasonable but this does not show that all emotion is unreasonable. An unreasonable fear of a flower, for example, can be explained in the following ways: ${ }^{9}$

1. "(His) reason for being afraid is expressible in a statcment, which, if true, would state a good reason for being afraid, but which is actually false and, in the given 
circumstances, obviously false .... (Baseless or unfounded fears.)" It is unreasonable to be afraid of a flower because it is poisonous when it is obvious (to the person who is afraid) that the flower is a daisy.

2. "He acknowledges that there is no danger, and yet he is afraid .... (Irrational fear.)" lt is unreasonable to be afraid of a flower if one admits that the flower is harmless.

3. "His reason for being afraid, although expressed in a true statement, states an extremely bad reason, or what might be called 'no reason' for being afraid ... (Superstitious fear.)" It is unreasonable to be afraid of a flower for the reason that anything that goes on graves, including flowers, is to be avoided.

4. "The object of his fear is an unsuitable one .... (a vain or neurotic fear.)" It is unreasonable to be afraid of a flower for the reason that flowers excrete pollen on one's clothes.

5. "The object of his fear is a suitable one, but his fear is too great ... (Abnormal or indiscriminate fear.)" It is unreasonable to fear poisonous flowers but not to the extent that one runs away even when seeing one in a glass display.

Reasonable or unreasonable experience of emotions depends on the reasonableness of beliefs, the reasonableness of the evaluation of these beliefs, and the reasonableness of what is desired. Emotions can also be displayed either reasonably or unreasonably. I will have more to say about this later.

\section{The Relationship of Emotion to Motivation}

Although commonly one says, for example, that I ran away because 1 was afraid, strictly speaking it is not fear which prompts my action; my action is prompted by my desire not to be hurt. Emotion and molivation are not the same. As I have shown. emotions are conceptually linked to certain motivating reasons.

R.S. Peters argues for a distinction between emotions and motives because, as he says, motives connect evaluations with actions while emotions connect evaluations with things that come over us. 10 Emotions are passive, says Peters; the only actions initiated by emotions are involuntary - our knees knock, we perspire, we blush. I, too, believe that emotions and motivations are different but 1 have argued for a conceptual connection between emotions and the desires and beliefs which make up certain motivations. Some emotions are followed by action but only if the desires to which they are con- 
nected would lead to action. For example, I run away because I desire not to be harmed by the mother bear. Since I desire not to be harmed and I see the situation as one in which I will be harmed if I stay, I run. The desire not to be harmed and the evaluation of the situation as one in which $I$ will be harmed, also result in my experience of fear. It is not the feeling of fear which motivates me to run. I run because I do not want to be harmed by the bear. Emotions may affect the efficacy of an action but emotions do not motivate actions. "My fear may lead me to use more (or less) force in applying the brakes, may increase (or decrease) my reaction time, or may lead me to think (or fail to think) of some useful stratagem." 11

An emotion is the necessary result of a particular motivating reason rather than the cause of a particular motivated action. Because emotions have no connection to action except by virtue of their link to certain desires, emotions appear to be superfluous. 12 The importance of "moral" emotions, at least, does not depend, however, on whether they motivate action. Moral emotions are important, as 1 argue in the next section, because of their significance to others.

\section{Moral Emotions}

One of Kant's major objections to recognizing emotions as morally significant was that he thought emotions to be natural to some and not to others. Consequently he thought that this would make "the capacity for moral worth a species of natural advantage" which would be "both logically incompatible with the notion of the moral, and also in some ultimate sense hideously unfair."13 I have argued that an experience of an emotion is a necessary result of desiring that someone is treated well or fairly. If someone desires another's welfare or fair treatment and the desire is either fulfilled or thwarted, a person will experience an emotion. If, for example, someone desires that another be treated fairly, has beliefs about what counts as fair treatment in the particular instance, and evaluates the situation as one in which someone is not treated fairly, the person will experience an emotion. If someone does not receive fair treatment when he or she desires fair treatment and the other conditions are met, this person will experience disappointment to anger depending on the severity of the situation. If the other individual flourishes, there will be an experience of satisfaction to joy. Similarly, if someone desires another's wellare, has beliefs about what counts as welfare in a particular situation, evaluates the situation as an instance in which someone's welfare is at stake, and if no one is able to help, this person will experience regret or sorrow. If he or she does not act because of a conflicting desire that is stronger than 
the desire for the other's welfare, there will be an experience of guilt or remorse. And so on.

Emotions such as sadness, anger, and joy are not only moral emotions. They may also be, for example, aesthetic emotions or selfinterested emotions. These emotions are moral emotions when they are the consequence of moral motivation. Emotions experienced as a result of being motivated by self-aggrandizement (for example, experiencing joy at receiving a benefit from someone's suffering) are not, of course, moral emotions, although they must be considered when accounting for moral emotions. 14 When a self-aggrandizing emotion is experienced in a moral situation, this emotion is an immoral emotion.

A moral emotion is conceptually connected to moral motivating reasons; it is part of a moral response and is morally significant to the recipient because, if properly displayed, it is an indication that the person responding actually desires the recipient's welfare or fair treatment. Because of the conceptual connection between emotion and desire, the sincere display of emotion indicates whether an agent's behaviour is the result of motivation directed at the person in the predicament or whether the behaviour has another motivation.

Experience or display of moral emotion does not always contribute to a moral response. When someone experiences extreme despair as a result of an evaluation of another's situation, while morally significant, the emotion may be harmful if it incapacitates this person from fulfilling his or her role as, for example, an adjudicator. An adjudicator who becomes overwhelmed by the plight of others in situations involving conflict may have the ability to adjudicate a problem but be unable to shift attention from the experience of emotion to the fair adjudication of a dilemma. Similarly, if someone is able to provide first aid to an accident victim but is overwhelmed by emotions and is unable to utilize these skills, the skills are useless. Because either excessive experience of emotion or excessive display of emotion may interfere with a moral response, this does not show that emotion should not be experienced or displayed. Someone is unjustified in his or her experience or emotion only if there is no justification for the desire and evaluated beliefs which are necessary for the emotion to occur. ${ }^{15}$ A particular display of an emotion is unjustified when it inhibits action or does not sincerely convey moral motivation to those in a moral situation.

Moral emotions, although superfluous to action, are not superfluous to the significance of the total moral response. Since a moral response is not indicated by action alone, the focus of motivation is central to whether emotional display can be evidence of someone's moral motivation. 16 


\section{Education of Moral Emotions}

Daniel DeNicola describes four different proposals for educating the emotions 17 which I will utilize so as to make comments about educating the moral emotions.

\section{Education of emotions as suppressing or channelling emotions}

The assumption of an educational program designed to suppress emotions is that "an emotional person is immature, maladjusted, and often irrational." 18 I have argued, on the other hand, that moral emotions are a necessary result of the ability to respond to moral motivating reasons. An educational program designed to assist people to suppress emotions would destroy the informational value of emotions since a sincere display of emotion is a signal to those in moral situations that someone cares.

"Rather than simply burn with anger, stew in resentment, or wither with grief, the emotionally educated person will produce an aesthetic object, strive for social reform, or otherwise act in a constructive manner..., 19 Although extreme experience of emotion can be debilitating, emotions do not have to be experienced in this way. Those who tend to have overwhelming experiences of emotion in moral situations must be helped to bring their emotions under control so that a moral response can be completed.

Although moral emotions may sometimes need to be controlled, they do not need to be channelled because moral emotions provide valuable information to those in moral predicaments about an agent's motivation. Immoral emotions - those experienced as a result of desires which conflict with desires for welfare and fair treatment of sentient beings - do, on the other hand, need to be controlled and channelled. Human emotions include jealousy, rage, envy, and selfpity and, while it is important to recognize these emotions in oneself and others, people must learn to control and channel these emotions. It is not sufficient, however, to merely redirect and control immoral emotions, however, since, as long as someone has these emotions, he or she has immoral desires. Control of immoral emotions must ultimately be concerned with the development of moral motivation.

\section{Education of emotions as becoming adept at identifying emotions}

It is important to be able to recognize when someone, including oneself, is experiencing an emotion. Being able to recognize personal experiences of emotion is an important step in coming to understand ones own motivation. Being able to recognize emotions in others is often necessary if one is to see a moral situation as a moral situation. If one is to respond to someone who is grieving, for example, one must be able to recognize grief. Moreover, when one is able to 
identify emotions felt by another, it is possible to understand the motivation of this person's response. Being aware of another's motivation is important to parents, leachers, friends, and others who might want to help someone become a moral person.

Being able to identify emotions in others is not to learn to have emotions oneself, however. Although important, this approach to education of emotions only involves education of cognitive skills and not actual experience of emotion.

\section{Education of emotions as increasing the justifiability of one's emotions}

An experience of an emotion is justified if one's beliefs, evaluation of beliefs, and desires are justified. The display of an emotion is justified if it is of appropriate intensity, duration, and sincerity. Justifiable display of emotion can be complex because display of emotion if affected by situational and cultural factors. 20 Crying exhorting, and gesturing, which reflect certain cultures' manifestations of anger, for example, may be morally significant to someone in a moral situation. On the other hand, such a display may accentuate this person's distress at what is seen as an overdisplay of emotion. In another culture, however, if someone does not display emotion in this way, his or her sincerity may be doubted.

Experience of moral emotion is developed concomitantly with the development of moral desires and with the development of beliefs and appraisals about moral situations. To be able to sincerely display moral emotion is also largely a matter of whether someone is morally motivated. Someone who is morally motivated is not likely to reign distress at another's misfortune in order, for example, to be ingratiated with that person. Morally significant display of emotion is dependent on an understanding of certain cultural expectations. One may not, however, always be able to significantly display emotions commensurate to cultural expectations and, at the same time, sincerely display these emotions.

4. Education of emotions as increasing sensitivity, freshness, scope, and complexity of emotions

DeNicola suggests that this entails a growth in ability to imagine and express alternative ways of feeling. 21 lt is possible to expand the intensity of different feelings. It is not clear, however, whether it is possible to increase emotional alternatives. Annette Bajer has this to say,

It is a peculiar but little wondered fact that we can draw up lists of feeling possibilities...aiming at a completed list, whereas no one would dream of trying to list all the ac- 
tions, or all the beliefs that are humanly possible.... We may discriminate more finely but not discover or invent a wholly new feeling... Whatever we think or do, however exciting the horizons there, and however inventive our expression of our feelings, our feelings themselves remain unoriginal original, restricted to the familiar round. 22

If the goal of education of emotions is to increase alternative ways of feeling this can, as Baier indicates, only apply to alternative ways to express emotion and not alternate ways to experience emotion. Baier wonders why this is so and leaves it as a question. She asks, "Are we necessarily restricted in our feelings..., not just contingently restricted, as we are, say, in our auditory powers, and if we are, what explains the necessity? Sociobiological constraints? The very idea of a social animal?" 23 A partial answer to these questions is that one's experience of emotion is necessarily tied to desire and evaluated beliefs. Consequently, how or what one feels cannot be affected without first affecting what one desires. This does not answer, however, the question why the desires we do have result in a circumscribed range of feelings.

I want to argue briefly that increasing sensitivity, freshness, scope, and complexity of moral emotions depends upon developing the intensity and scope of benevolent and just desires and that these in turn are affected by what we regularly attend to.

Moral change and moral achievement are slow; we are not... able suddenly to alter ourselves since we cannot suddenly alter what we see and, ergo, what we desire and are compelled by 24

Someone cannot just decide to be morally motivated because someone cannot just decide to desire something. Murdoch's notion that what we regularly attend to affects "what we desire and are compelled by" is very important to understanding how someone is motivated and consequently what sort of person he or she is.

What someone is, as Murdoch points out, depends upon a lifelong process of what is looked at and seen by the person. Moral life is not just a series of discrete instances in which an autonomous individual considers a number of alternatives which are unaffected by other life experiences. Any decision someone makes in a moral situation is continuous with the rest of the person's life. What a person does in a particular situation is already determined by what one has given one's attention to most often prior to the moral situation. 25 What we give regular attention to builds up structures of value 
around us so that, as Murdoch says, "By the time the moment of choice has arrived the quality of attention has probably determined the nature of the act." 26

This process of directing one's attention away from oneself is not an easy process; it is not something one can merely decide to do. Murdoch says that the struggle is to keep one's attention on the real situation and prevent it from "returning surreptitiously to the self with consolations of self-pity, resentment, fantasy, and despair." 27 The struggle to direct one's attention away from personal fantasy is a struggle that occurs throughout life and not only during particular moral choices.

Objects of positive looking at include, says Murdoch, "anything which alters consciousness in the direction of unselfishness, objectivity and realism." 28 Murdoch provides a particularly poignant and lovely example of this:

I am looking out my window in an anxious and resentful state of mind, oblivious of my surroundings, brooding perhaps on some damage to my prestige. Then suddenly I observe a hovering kestrel. In a moment everything is altered. The brooding self with its hurt vanity has disappeared. There is nothing now but the kestrel. And when I return to thinking of the other matter it seems less important. And of course this is something which we may also do deliberately: give attention to nature in order to clear our minds of selfish care." 29

Since moral emotions are experienced by the person who desires others' welfare and fair treatment, education of moral emotions is primarily a matter of educating these desires. Education of moral desires is a lifelong process which consists primarily in directing attention to exemplary objects and events. There are two implications to this. One is that there is a role for education in actively directing attention. (There is no implication that this occurs only in schools.) Second, there is the implication that the environment must have exemplary objects and events which can be attended to. It is not, however, a very helpful solution to suggest to those living in squalor that they would be better off if they would shift their attention to exemplary objects and events. In many cases, only a massive redistribution of resources would make it possible for these people to have an opportunity for "positive looking at."

Because of the conceptual connection of moral emotions to moral desires, education of moral emotions is concerned with the development of moral desires through the direction of attention 
within communities which have exemplary objects and events to which people can attend. As moral desires are acquired, moral education must also help people to become aware of the concomitant emotions they experience. This understanding must, in turn, be utilized to assist people to learn to control the display of moral emotions in order that motivation is sincerely and significantly indicated to those in moral situations. 


\section{Notes}

1'This paper was originally presented by me at the Learned Societies' Meetings in Hamilton, Ontario, June 3, 1987. I would like to thank William Hare for his helpful comments on that paper.

2G. Pitcher, "Emotion," in Emotion and the Development of Reason, eds. R.F. Dearden, P.H. Hirst, and R.S. Peters, (London: Routledge and Kegan Paul, 1972), 380.

${ }^{3}$ William James, Principles of Psychology, Vol. Il (New York: Macmillan, 1980), 449-50.

${ }^{4}$ Magda, Arnold, "Feelings and Emotions as Dynamic Factors in Personality Integration," in The Nature of Emotion, ed. Magda Arnold (New York: Penguin Books, 1968), 46.

5This is R.S. Peters' example from "Motivation, Emotion and the Conceptual Schemes of Common Sense," in Psychology and Ethical Development, (London: George Allen and Unwin Ltd., 1974).

${ }^{6}$ William Lyons, Emotion, (Cambridge University Press, 1980), 35.

\section{7 lbid., 50}

${ }^{8}$ The exception to this might be emotions which are conditioned such that a person responds with an "emotion" on a certain cue. But conditioned "emotions" are not unlike drug induced "emotions" in which the person could, for example, feel angry but not be angry.

${ }^{9}$ Pitcher, op. cit., 373.

10 R.S. Peters, "The Education of the Emotions," op. cit., 178.

11 Jerome A. Schaffer, "An Assessment of Emotion," American Philosophical Quarterly, 20, 1983, 166.

12 Ibid., 163.

13 Bernard Williams, "Morality and the Emotions," Problems of the Self, (Cambridge: At the University Press, 1973), 228.

${ }^{14}$ William Hare clarified this point for me.

15 Schaffer, op. cit., 165.

$16_{\text {Schaffer rightly points out that, "there are disadvantages to }}$ this arrangement. We can be misled; physiological/psychological states can be feigned or suppressed, and their presence or absence can be misinterpreted." Ibid., 167.

17 Daniel DeNicola, "The Education of the Emotions," Philosophy of Education Proceedings, 1979, $210-223$.

18 Ibid., 213. 
19 Ibid., 214.

20 lbid., 215.

21 Ibid., 216.

22 Annette Baier, Postures of the Mind: Essays on Mind and Morals, (Minneapolis: University of Minnesota Press, 1985), 123-124.

23 Jbid., 124.

${ }^{24}$ Iris Murdoch, The Sovereignty of Good, (Routledge and Kegan Paul, 1970), 39.

$25_{\text {Ibid., } 17 .}$

$26_{\text {Ibid., } 67 .}$

27 lbid., 91.

28 Ibid., 84.

29 lbid., 84. 